\title{
Effect of coupled UV-A and UV-C LEDs on both microbiological and chemical pollution of urban wastewaters
}

\author{
A.-C. Chevremont ${ }^{\mathrm{a}, \mathrm{b}, *}$, A.-M. Farnet ${ }^{\mathrm{b}}$, B. Coulomb ${ }^{\text {a }}$, J.-L. Boudenne ${ }^{\mathrm{a}}$

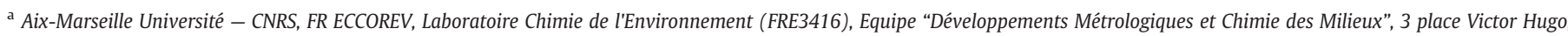 \\ case 29, 13331 Marseille Cedex 3, France

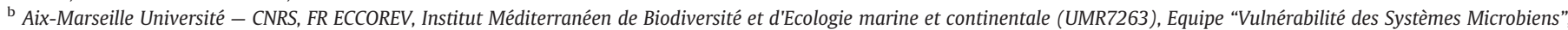 \\ Avenue Escadrille Normandie-Niemen, Boîte 452, 13397 Marseille Cedex 20, France
}

Keywords:

Bacteria inactivation

Coupled wavelengths

Ultraviolet light-emitting diodes (UV-LED)

Water recycling

Photooxidation

\begin{abstract}
A B S T R A C T
Wastewater reuse for irrigation is an interesting alternative for many Mediterranean countries suffering from water shortages. The development of new technologies for water recycling is a priority for these countries. In this study we test the efficiency of UV-LEDs (Ultraviolet-Light-Emitting Diodes) emitting UV-A or UV-C radiations, used alone or coupled, on bacterial and chemical indicators. We monitored the survival of fecal bioindicators found in urban wastewaters and the oxidation of creatinine and phenol which represent either conventional organic matter or the aromatic part of pollution respectively. It appears that coupling UV-A/UV-C i) achieves microbial reduction in wastewater more efficiently than when a UV-LED is used alone, and ii) oxidizes up to $37 \%$ of creatinine and phenol, a result comparable to that commonly obtained with photoreactants such as $\mathrm{TiO}_{2}$.
\end{abstract}

\section{Introduction}

Reuse of wastewater for irrigation or watering of green spaces is an interesting alternative for many Mediterranean countries suffering from water shortages (Nasser et al., 2006; Palese et al., 2009). Microbiological quality of water is a major parameter to take into account for the reuse of wastewater. French legislation relating to the reuse of water - issued from urban wastewater treatment plants - for irrigation of crops or gardens (Decree of August 2nd, 2010) focuses on fecal enterococci and coliforms. They are indeed the most relevant indicators of fecal pollution, giving information about the presence of major pathogens of human origin in wastewaters (Evanson and Ambrose, 2006). Moreover, their quantification is simple and economical (Molleda et al., 2008). This decree recommends, for water which can be used for irrigation of different kind of crops, a reduction of at least $2 \log$ of fecal enterococci and number of fecal coliforms reduced at least at 100,000 cfu/100 mL.

Different processes have been used to treat wastewater intended to be reused for irrigation. Water disinfection technologies based on UV (Ultraviolet) radiations have been shown to be efficient (Hijnen et

\footnotetext{
* Corresponding author at: Aix-Marseille Université - CNRS, FR ECCOREV, Laboratoire Chimie de l'Environnement (FRE3416), Equipe "Développements Métrologiques et Chimie des Milieux", 3 place Victor Hugo, 5 case 29, 13331 Marseille Cedex 3, France Tel.: + 33 491288528; fax: + 33491288190 .

E-mail address: anne-celine.chevremont@imbe.fr (A.-C. Chevremont).
}

al., 2006). UV radiation causes damage to DNA, preventing replication, transcription and thus translation. However, many microorganisms can repair damage to DNA through repair enzyme systems. Two different mechanisms are involved: photoreactivation and dark-repair (Oguma et al., 2001; Witkin, 1976). UV radiations cause direct oxidation of DNA molecules but also activate the production of reactive intermediates (such as hydroxyl radicals), from water and organic matter present in the effluent, which oxidize membrane and proteins of microorganisms. These reactive intermediates are also able to oxidize complex chemical pollutants present in effluent: pharmaceuticals (Kim et al., 2009; Rizzo et al., 2009), endocrine disruptors (Chen et al., 2007), polycyclic aromatic hydrocarbons (Woo et al., 2009), linear alkylbenzene sulfonate (Tabrizi and Mehrvar, 2006) and pesticides (Badawy et al., 2006). Liberti et al. (2003) have shown that, at UV doses used for disinfection (around $400 \mathrm{~J} / \mathrm{m}^{2}$ ), there was no formation of oxidation by-products (potentially more toxic than initial molecules) during wastewater treatment by UV.

Wavelength mainly used in UV processes is $254 \mathrm{~nm}$, because it is close to the wavelength of DNA maximum absorption. UV radiations are generally emitted by mercury vapor lamps which are used in wastewater treatment or water purification. However, mercury vapor lamps have many disadvantages: large size, low resistance to shock and its operation requires a lot of energy. Moreover, these lamps have a short lifespan of about 4000-10,000 h and contain mercury, a major pollutant. Use of LEDs (Light-Emitting Diodes) to produce UV radiations has many advantages. LEDs are very compact, shock-resistant, do not 
require much energy and life is greater than 100,000 h (Crawford et al., 2005). In addition, LEDs are free of toxic or polluting substances: they are made of aluminum nitride (AIN) or gallium and aluminum nitride (AlGaN) that are not toxic (Vilhunen et al., 2009). In addition, LEDs use electricity more efficiently, producing little heat. However, few studies have so far been conducted on water disinfection by UV-LED (Ultraviolet-Light-Emitting Diode) technology. Vilhunen et al. (2009) have shown that UV-LED irradiations were effective in eliminating Escherichia coli.

In this study, we test the efficiency of UV-LED system on the microorganism content in sewage effluents. We follow the reduction of total microorganisms growing at $37{ }^{\circ} \mathrm{C}$ and of fecal indicators which are total coliforms, fecal coliforms and fecal enterococci. We also test the oxidation of pollutants by UV-LED system using creatinine (a metabolic waste) to represent conventional organic matter and phenol to represent the aromatic part of pollution. Creatinine is a nitrogen-containing compound mostly found in urine (Antoniou and Dionysiou, 2007). Phenol is an aromatic compound widely found in wastewater and refractory to biodegradation.

Different wavelengths are tested, and used alone or combined, to advantageously combining the direct germicidal effect of UV-C with the indirect effect of intermediates produced by UVB-A. Wavelengths 254 and $280 \mathrm{~nm}$ are potentially the most efficient to eliminate microorganisms since they are close to the DNA maximum absorption rate and are responsible for the formation of pyrimidine dimers. This wavelength range has been proved to cause damage on both DNA and proteins of adenoviruses known as waterborne pathogens (Linden et al., 2007; Eischeid et al., 2009). Wavelengths 365 and $405 \mathrm{~nm}$ are included in the UV-A range which is known to induce the formation of active substances having lethal effects (Oppezzo and Pizarro, 2001) and to induce various photochemical processes leading to the degradation of pollutants (Zepp et al., 1995). The coupling wavelength is expected to combine these two effects.

A preliminary study on pure bacterial cultures (Chevremont et al., 2012) has shown that coupling UV-A/UV-C appears to be a promising technique for disinfection. Here, the objective was to investigate whether the combined effect of UV-A/UV-C irradiation was as efficient on micro-organisms in a more complex medium such as a wastewater effluent. Chemical and microbial characteristics of the effluent such as turbidity or microbial diversity may indeed affect UV LED potential of disinfection. To do so, we test, under the conditions previously described (Chevremont et al., 2012), the UV-LED system as a tertiary treatment on an effluent collected in a wastewater treatment plant located in southeastern France, after a primary treatment (sedimentation stage) and a secondary treatment (activated sludges).

\section{Material and methods}

\subsection{Experimental setup}

Experimental setup is described in Chevremont et al. (2012). Briefly, four LEDs (manufactured by Seoul Optodevice Co., Ltd., Korea) emitting at 254, 280, 365 or $405 \mathrm{~nm}$ respectively were used throughout experiments, separately or coupled as follows: 254/ $365 \mathrm{~nm}, 254 / 405 \mathrm{~nm}, 280 / 365 \mathrm{~nm}$ and 280/405 nm. The circuit was connected to a power supply (TTI EL302R Power Supply). All four LEDs were used with their maximal amperage: LED emitting at $254 \mathrm{~nm}$ has a maximum intensity of $115 \mathrm{~mA}$, and the three others $(280,365$ and $405 \mathrm{~nm}$ ) were used also at their maximum amperage, i.e. at $77 \mathrm{~mA}$, $22 \mathrm{~mA}$ and $46 \mathrm{~mA}$, respectively. Distance between LEDs and effluents was set at $1 \mathrm{~cm}$ and aliquots of each effluent $(10 \mathrm{~mL})$ were placed in Petri dishes ( $55 \mathrm{~mm}$ diameter) and exposed for $60 \mathrm{~s}$ at different wavelengths or wavelength coupling. UV exposure was performed at room temperature $\left(25^{\circ} \mathrm{C}\right.$ ). In a first study (Chevremont et al., 2012) the previous conditions used on a high-density suspension $\left(10^{7} \mathrm{cfu} / \mathrm{mL}\right)$ of exponentially growing bacteria - more susceptible to UV - were also selected here. Indeed, in wastewaters, bacteria in stationary phase are less susceptible to UV but are less numerous $\left(10^{4} \mathrm{cfu} / \mathrm{mL}\right)$ and the $\log$ of reduction requested is weaker. Kinetic studies were carried out with $250 \mathrm{~mL}$ of effluent placed into a crystallizing dish (14-cm diameter) that was exposed for $60 \mathrm{~min}$ to $280 / 365 \mathrm{~nm}$ under magnetic stirring. An aliquot of $2 \mathrm{~mL}$ was collected every $15 \mathrm{~min}$ for bacterial enumeration. An assay was also performed with $500 \mathrm{~mL}$ of effluent in a crystallizing dish (14-cm diameter) with an exposition time of $30 \mathrm{~min}$ to 280/ $365 \mathrm{~nm}$.

\subsection{Effluent}

The effluent used was collected from the outlet of a wastewater treatment plant (6650 equivalent inhabitants, average flow rate $800 \mathrm{~m}^{3}$ /day) after biological treatment by activated sludges. Mesophilic bacteria, fecal streptococci, total coliforms and fecal coliforms were enumerated using selective culture media. Total Suspended Solids (TSS) were determined by filtering $100 \mathrm{~mL}$ of effluent on GF-D filter, drying of filter for $16 \mathrm{~h}$ at $90{ }^{\circ} \mathrm{C}$ and weighting of remaining solids. Turbidity was measured with a portable turbidimeter (Turb 430 IR/T, WTW, Weilheim, Germany).

The chemical oxygen demand (COD) of water has been determined by the potassium dichromate method according to ISO 15705:2002. Briefly, $2 \mathrm{~mL}$ of sample are introduced in COD tubes (range 0-1500 mg $\mathrm{O}_{2} / \mathrm{L}$ ) purchased from Aqualytic (Dortmund, Germany), before heating at $150{ }^{\circ} \mathrm{C}$ for $2 \mathrm{~h}$ (Thermoreaktor 300 from Merck, Darmstadt, Germany). COD values are then determined by an AL800 photometer from Aqualytic, previously calibrated with COD standard solutions.

\subsection{Enumeration of microorganisms}

After irradiation by the UV-LED system, $1 \mathrm{~mL}$ of effluent was properly diluted and plated on medium Tryptone Soy Agar (TSA) for total microorganisms growing at $37^{\circ} \mathrm{C}$, on medium Slanetz et Bartley for fecal enterococci and on a medium based on 2-3-5 triphenyltetrazolium chloride (TTC) plus tergitol for coliforms. Cultures were incubated for 24 h at $37^{\circ} \mathrm{C}$ or $44^{\circ} \mathrm{C}$ before enumeration of bacteria. Each experiment was realized in triplicate. The number of bacteria was expressed in cfu/ $\mathrm{mL}$ that allowed us to calculate an inactivation percentage or a log survival ratio (Mori et al., 2007):

Log survival ratio $=\log \left(\mathrm{N}_{\mathrm{UV}} / \mathrm{N}_{\mathrm{C}}\right)$

where $\mathrm{N}_{\mathrm{UV}}$ is the number of bacteria in the UV irradiated effluent, and $\mathrm{N}_{\mathrm{C}}$ is the number of bacteria before irradiation, used here as control.

This ratio is calculated in order to highlight the first-order disinfection model of Chick-Watson, a linear relationship between log inactivation and UV dose applied. This relation is described by the formula (Hijnen et al., 2006):

$\log \left(\mathrm{N}_{\mathrm{UV}} / \mathrm{N}_{\mathrm{C}}\right)=-\mathrm{k} *$ UV dose

\subsection{Reactivation experiments}

After irradiation with the different wavelengths or coupled wavelengths, the effluent samples were kept at room temperature $\left(25^{\circ} \mathrm{C}\right)$ and ambient light during $20 \mathrm{~h}$. To investigate a possible bacterial reactivation $1 \mathrm{ml}$ of each sample was then removed and plated on culture media as described in Section 2.3. Cultures were then incubated for $24 \mathrm{~h}$ at $37^{\circ} \mathrm{C}$ or $44^{\circ} \mathrm{C}$ before enumeration of bacteria. Each experiment was realized in triplicate. 


\subsection{Luminous flux}

The luminous flux emitted by each LED (in Watts) was measured by actinometry (Edelahi, 2004). Ten milliliters of a $30 \mathrm{mM}$ potassium ferrioxalate solution were irradiated with each LED for $0,5,10$, and $20 \mathrm{~min}$. At the end of each irradiation, $1 \mathrm{~mL}$ of the potassium ferrioxalate solution irradiated is placed in a $20 \mathrm{~mL}$ volumetric flask with $1.5 \mathrm{~mL}$ of a buffer solution $\left(0.1 \mathrm{~N} \mathrm{H}_{2} \mathrm{SO}_{4}, 0.1 \mathrm{~N} \mathrm{CH}_{3} \mathrm{COONa}\right)$ and $2 \mathrm{~mL}$ of a solution of 1,10 -phenanthroline monohydrate $(0.1 \%)$ qs $20 \mathrm{~mL}$ ultrapure water. Then the mixture was stirred in the dark for $30 \mathrm{~min}$. The ferrous ions produced during the photolysis of potassium ferrioxalate solution formed a red complex with phenanthroline. This complex was spectrophotometrically determined at $510 \mathrm{~nm}$. The number of $\mathrm{Fe}^{2+}$ ions in the solution can then be determined from the following equation:

$\mathrm{n}_{\mathrm{Fe}^{2+}}=\left(\mathrm{N} * \mathrm{~V}_{1} * \mathrm{~V}_{3} * \mathrm{DO}_{510}\right) /\left(\mathrm{V}_{2} * \mathrm{l} * \varepsilon * 10^{3}\right)$

where $\mathrm{N}$ is the Avogadro number, $\mathrm{V}_{1}$ the volume of the irradiated solution $(\mathrm{mL}), \mathrm{V}_{2}$ the volume of $\mathrm{V}_{1}$ taken for analysis $(\mathrm{mL}), \mathrm{V}_{3}$ the final volume after dilution of $\mathrm{V}_{2}(\mathrm{~mL}), \mathrm{DO}_{510}$ the absorbance of the complex measured at $510 \mathrm{~nm}$ in the $\mathrm{V}_{3}$ solution, $\varepsilon$ the coefficient of molar extinction of the complex phenanthroline- $\mathrm{Fe}^{2+}\left(\mathrm{mol}^{-1}\right.$.L.cm $\left.{ }^{-1}\right)$ and 1 the optical path length $(\mathrm{cm})$.

The number of $\mathrm{Fe}^{2+}$ ions is used to calculate the incident photon flux (photons.s ${ }^{-1}$ ) using the following formula:

$\mathrm{P}_{0, \lambda}=\mathrm{n}_{\mathrm{Fe}^{2+}} /\left(\phi_{\mathrm{Ac}} * \mathrm{t}\right)$

where $\varphi_{\mathrm{Ac}}$ is the quantum yield of the actinometer at the wavelength of $254 \mathrm{~nm}$ and the irradiation time (s).

The incident photon flux is used to calculate the power emitted by each LED:

$\mathrm{P}_{\mathrm{e}}=((\mathrm{h} * \mathrm{c}) / \lambda) * \mathrm{P}_{0, \lambda}$

where $\mathrm{h}$ is the Planck's constant, $\mathrm{c}$ is the celerity of light $\left(\mathrm{m} . \mathrm{s}^{-1}\right)$ and $\lambda$ the wavelength $(\mathrm{m})$.

The luminous flux emitted is expressed in Watts. Dividing this result by the irradiated surface may allow one to determine the irradiance (or flux of radiation in $\mathrm{W} / \mathrm{m}^{2}$ ).

\subsection{HPLC analysis}

For chemical kinetics $20 \mathrm{mg} . \mathrm{L}^{-1}$ of creatinine or phenol were added to $250 \mathrm{~mL}$ of effluent and exposed to the UV-LED system, to test their potential oxidation in this complex medium. A UV-HPLC system (Waters), equipped with a C18 Reverse Phase column (Merck, $4.6 \times 250 \mathrm{~mm}$ ), was used with, as elution solvents: solvent $A$, (water/ trifluoro acetic acid $0.1 \%$ )/acetonitrile $70 / 30 \mathrm{v} / \mathrm{v}$, and solvent $\mathrm{B}$ (water/trifluoro acetic acid 0.1\%)/acetonitrile 10/90 v/v. The gradient mode used was the following: 0 to $5 \mathrm{~min}, \mathrm{~A} 100 \% ; 5$ to $15 \mathrm{~min}, \mathrm{~A} 100 \%$ to $\mathrm{B} 100 \%$; 15 to $25 \mathrm{~min}$ B $100 \%$ (flow rate $1 \mathrm{ml} \mathrm{min}^{-1}$ ). The detection wavelengths were respectively 220 and $270 \mathrm{~nm}$ for creatinine and phenol. The calibration curves were carried out with concentrations ranging from 0 to $1 \mathrm{mM}$ for creatinine $\left(\mathrm{r}^{2}=0.9706\right)$ and from 0 to $1.4 \mathrm{mM}$ for phenol $\left(\mathrm{r}^{2}=0.9895\right)$. Each sample was analysed after various irradiation durations to determine the disappearance yields of these compounds.

\subsection{Statistical analysis}

In order to overcome the assumption of normality of the samples, the nonparametric test of Kruskal and Wallis was used to test the effect of different wavelengths on microbial disappearance. In the case of a significant effect compared to the effluent non-irradiated, a test of Dunn and Bonferroni correction were performed to further identify the wavelengths responsible for this effect. To compare the effectiveness of the system on two different volumes, the normality of distribution was tested with the Shapiro-Wilk test $(p>0.05)$ and the homogeneity of variance with Fisher test $(p>0.05)$. The results for each volume tested (and for each bacterial type) were compared with Student parametric two-tailed test for two independent samples. In the case of paired samples, a Friedman test for paired samples was applied to the data, followed by a test of Nemenyi and Bonferroni correction if necessary.

\section{Results and discussion}

Four LEDs emitting at different wavelengths (254, 280, 365 and $405 \mathrm{~nm}$ ) were used separately or combined as follows 254/365, 254/405, 280/365 and 280/405 $\mathrm{nm}$ to couple UV-C and UV-A. Their effectiveness was tested on an effluent collected in an urban wastewater treatment plant, after physic-chemical and biological treatments. After these twostage treatments, the effluents were still highly turbid with a value of 71.5 NTU (Nephelometric Turbidity Unit). The effluent was also characterized by a $210 \mathrm{mg} \mathrm{O} / \mathrm{L}$ COD value and a TSS value of $150 \mathrm{mg} /$ L. The French recommendation of 22 June, 2007 on the quality of treated urban wastewaters sets maximum discharge values at $125 \mathrm{mg} \mathrm{O} / \mathrm{L}$ (COD) and $35 \mathrm{mg} / \mathrm{L}$ (TSS). These results revealed thus that the treatments in this plant are not adequate. It was thus interesting to test the potentialities of UV-LED for wastewater refinery treatment upon these samples.

\subsection{Microbiological assays}

At the output of this wastewater treatment plant, the effluent contains $3.10^{4} \mathrm{cfu} / \mathrm{mL}$ of mesophilic bacteria, $1.6 .10^{3} \mathrm{cfu} / \mathrm{mL}$ of fecal enterococci, $8.3 .10^{3} \mathrm{cfu} / \mathrm{mL}$ of total coliforms and $1.9 .10^{3} \mathrm{cfu} / \mathrm{mL}$ of fecal coliforms. These bacteria were chosen because they are used as fecal pollution indicators and they highlighted thus the presence of a potentially pathogenic bacterial cohort.

The luminous flux emitted by each LED was measured by actinometry and was $0.29,0.55,1.69$ and $10.23 \mathrm{~mW}$ for the LEDs emitting at 254, 280, 365 and $405 \mathrm{~nm}$ respectively. LEDs emitting at 254 and $280 \mathrm{~nm}$ are less powerful but are known to have a high germicidal effect.

Ten milliliters of effluent were exposed to UV radiations for $60 \mathrm{~s}$. For this exposure time the UV dose (which is the product of UV irradiance in $\mathrm{mW} / \mathrm{cm}^{2}$ and the exposure time in seconds) values were $0.73,1.37$, 4.22 and $25.58 \mathrm{~mJ} / \mathrm{cm}^{2}$ for $254 \mathrm{~nm}, 280 \mathrm{~nm}, 365 \mathrm{~nm}$ and $405 \mathrm{~nm}$ respectively. The tested bacterial communities (mesophilic bacteria, fecal enterococci, total coliforms and fecal coliforms) were counted after treatment with single or coupled wavelengths and results are presented Fig. 1. Fig. 1a shows that only the coupling wavelengths $280 / 365 \mathrm{~nm}$ and $280 / 405 \mathrm{~nm}$ can achieve a significant reduction in mesophilic bacteria compared to non-irradiated control (Kruskal-Wallis, $\mathrm{p}<0.05$, and multiple comparisons of means by pairs according to the Dunn procedure). Additionally, all the coupling wavelengths tested are significantly more effective than those used separately for fecal enterococci, total coliforms and fecal coliforms as shown in Figs. 1b, $c$ and d (test of Kruskal-Wallis, $\mathrm{p}<0.05$, and multiple comparisons of means by pairs according to the Dunn procedure). This is in accordance with the results obtained with certain strains tested in our previous paper (Chevremont et al., 2012). Here, our results show that the LED emitting at the wavelength usually used in water treatment $(253.7 \mathrm{~nm})$, and emitted by low-pressure mercury vapor lamps, is not powerful enough in its commercial version to have the greatest bactericidal effect. However, at a UV dose lower than that of LED emitting at $405 \mathrm{~nm}$ $\left(0.73 \mathrm{~mJ} / \mathrm{cm}^{2}\right.$ vs $\left.25.58 \mathrm{~mJ} / \mathrm{cm}^{2}\right)$, the LED emitting at $254 \mathrm{~nm}$ yields to the same result. This suggests that for a similar UV dose $\left(25.58 \mathrm{~mJ} / \mathrm{cm}^{2}\right)$, the LED emitting at $254 \mathrm{~nm}$ would have led to a better bacterial 
a)

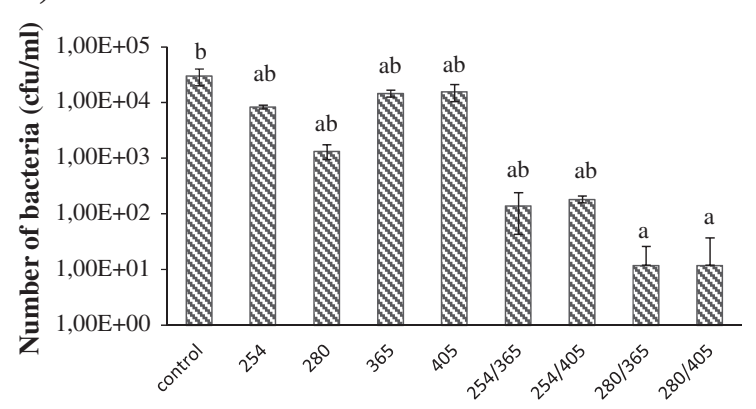

Wavelengths (nm)

c)

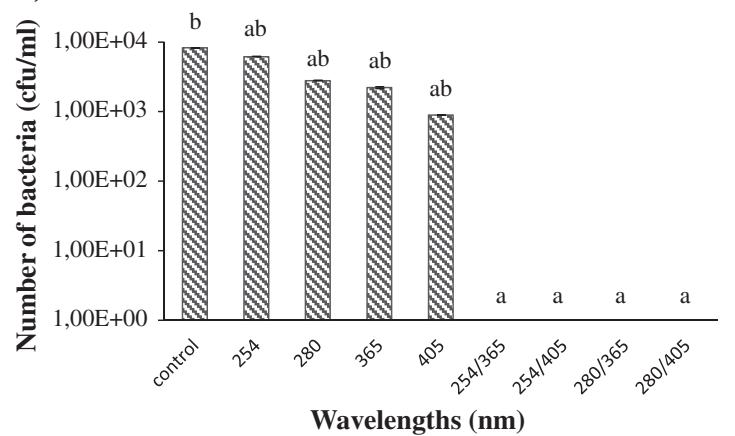

b)

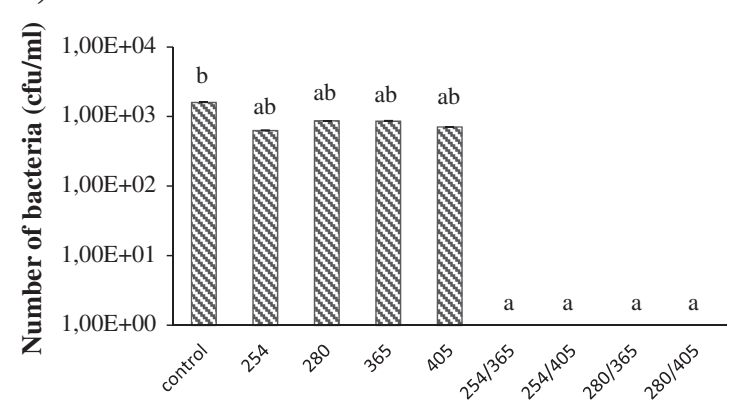

Wavelengths (nm)

d)

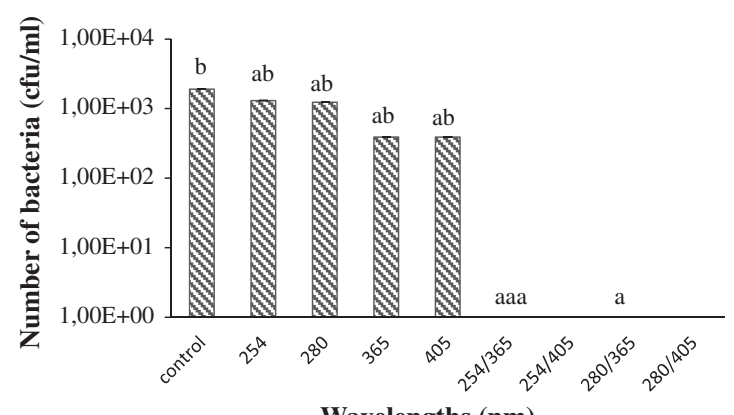

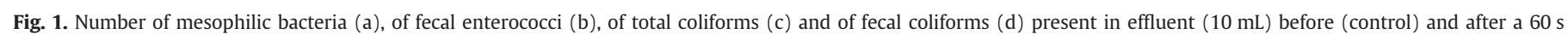

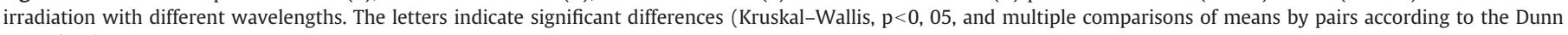
procedure).

reduction. Oppezzo and Pizarro (2001) have shown that at higher UV doses $\left(120 \mathrm{~J} / \mathrm{cm}^{2}\right)$ emitted by a bench with two ultraviolet tubes, UV-A prevented the bacterial growth of E. coli and Enterobacter cloacae. Here, wavelengths used separately do not show bactericidal effects while the coupling wavelengths lead to a significant bacterial reduction. In addition, the most effective coupled wavelengths (280/365 nm and 280/ $405 \mathrm{~nm}$ ), leading to a significant reduction in total mesophilic bacteria, do not involve $254 \mathrm{~nm}$ as the UV-C wavelength but $280 \mathrm{~nm}$. Furthermore, the use of coupling wavelengths allowed a total disappearance of fecal enterococci, total coliforms and fecal coliforms in the effluent. Coupled wavelengths combine two UV properties: the bactericidal power of UV-C (200-280 nm) and the ability of UV-A (315-400 nm) to react with oxygen dissolved in water and to produce reactive forms of oxygen-oxygen free radicals and hydrogen peroxides (Close et al., 2006). UV-A is responsible for oxidative disturbance of bacterial membranes by producing active species and also photo-damage tRNAs, which significantly slows protein synthesis (Oppezzo and Pizarro, 2001). UV-C is known to act directly on the DNA molecule: they lead to the formation of pyrimidine dimers, which prevents DNA replication. Such DNA damage can be repaired by the enzyme photolyase, whereas damage to bacterial membranes cannot be repaired (Oguma et al., 2002).

The coupling of wavelengths may also reduce the bacterial reactivation with this dual action of UV-C and UV-A. Twenty hours after irradiation, each bacterial type was counted to check whether DNA reparation had occurred: viable cells of fecal enterococci, total coliforms and fecal coliforms remain undetectable after $20 \mathrm{~h}$ (data not shown) at ambient temperature $\left(25^{\circ} \mathrm{C}\right.$ ) and light (Wilcoxon test for paired samples, $\mathrm{p}>0.05$ ). This can be explained by the combination of two types of UV. The bactericidal power of UV-A is lower than that of UV-C, but UV-A may act indirectly on bacteria by increasing the levels of reactive oxygen species as superoxide anion radicals, hydroxyl radicals, hydrogen peroxide, and singlet oxygen (Hamamoto et al., 2007).
In order to optimize the UV-LEDs system, we tested its effects on larger volumes ( 250 and $500 \mathrm{~mL}$ ) of effluent. Kinetics of bacterial reduction was thus performed on $250 \mathrm{~mL}$ of effluent volume. The preliminary tests with $10 \mathrm{~mL}$ showed that coupling wavelengths reduce significantly the amount of mesophilic bacteria and fecal indicators. We have therefore carried out the tests on larger volumes of effluent using the coupling $280 / 365 \mathrm{~nm}$. The irradiation was maintained for $60 \mathrm{~min}$ and an aliquot of $2 \mathrm{~mL}$ was collected every $15 \mathrm{~min}$ and then cultured (with the adequate dilution) on culture media specific for each bacterial type. Fig. 2 shows the log survival ratio of mesophilic bacteria, fecal enterococci, total coliforms and fecal coliforms in $250 \mathrm{~mL}$ of effluent as a function of exposure time at $280 / 365 \mathrm{~nm}$. The survival ratio of the bacteria tested here is clearly positively correlated $\left(r^{2}\right.$ greater than 0.9) with the UV exposure duration: the longer exposure time is, the lower the survival ratio of bacteria is. This means that the number of mesophilic bacteria, fecal enterococci, total and fecal coliforms in the effluent decreases with irradiation time according to a Chick-Watson first-order reaction (Hijnen et al., 2006). For the four bacterial types tested, the log survival ratio, after 30 min of UV exposure, is significantly different from the non-irradiated control's one (Friedman test for paired samples, $\mathrm{p}<0.05$, and multiple comparisons by pairs, according to the Nemenyi procedure). When treating $250 \mathrm{~mL}$ of effluent, $30 \mathrm{~min}$ of irradiation at $280 / 365 \mathrm{~nm}$ is sufficient to obtain a significant bacterial reduction (Friedman test for paired samples, $\mathrm{p}<0.05$ ). Table 1 shows the bacterial reduction (in $\log$ ) and the number of bacteria remaining in the effluent (in cfu/100 mL) after irradiation for each bacterial type tested. Bold valuesare those that concern the French legislation intended for treated wastewater reuse for irrigation. Table 1 shows that objectives are indeed achieved: the reduction of fecal enterococci exceeds $2 \log$ and there are only $444 \mathrm{cfu} / 100 \mathrm{~mL}$ remaining fecal coliforms in the effluent after irradiation. The decree of August 2nd, 2010 indicates that, under these conditions, this water can be used for flower cultivation, garden nurseries, cereal and forage crops, fruit and forest exploitation. 
a)

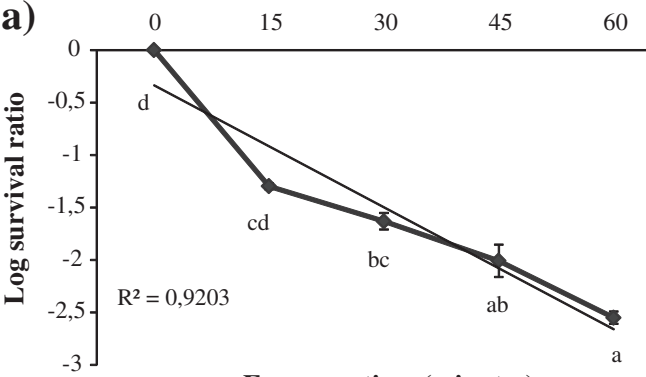

Exposure time (minutes)

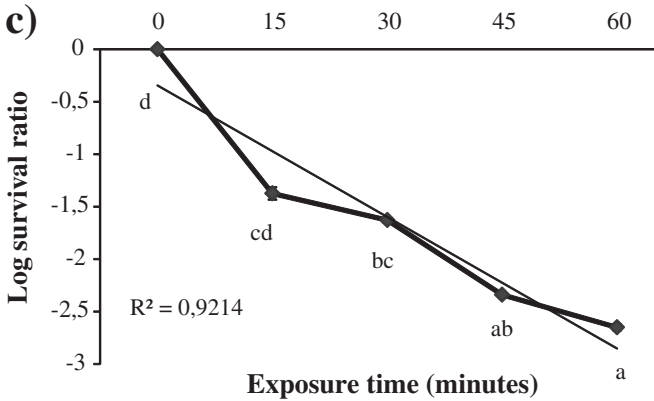

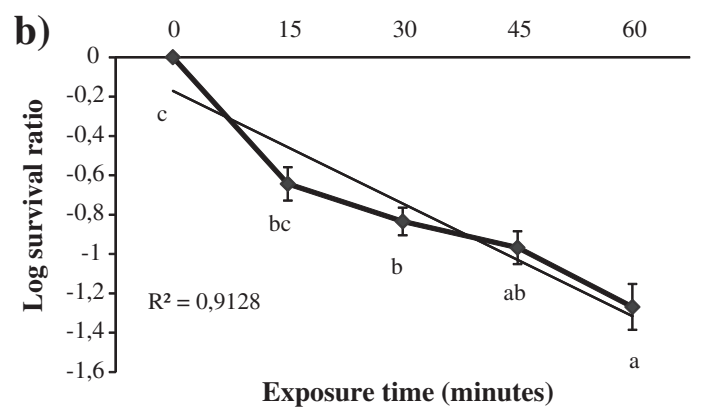

Exposure time (minutes)

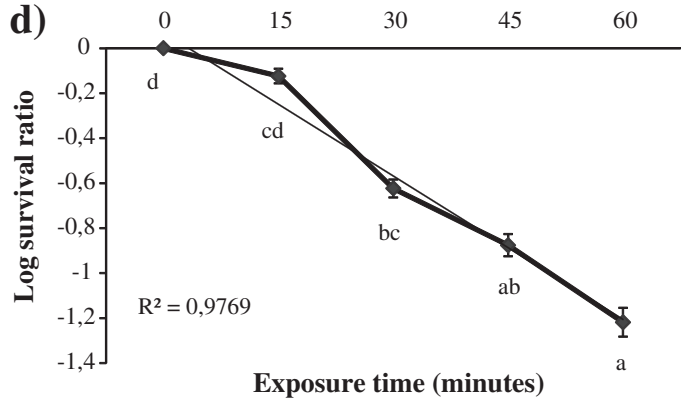

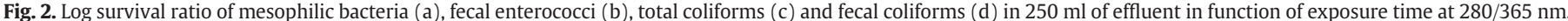

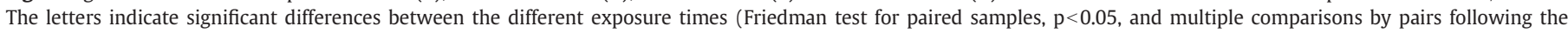
Nemenyi procedure).

Different parameters influence bacterial survival in the effluent: the wavelengths used (single or coupled), the exposure durations, the turbidity and the thickness of the aqueous layer to be treated may also play a role in bacterial response to UVs. When increasing the volume of the effluent in the crystallizing dish, it increases the thickness of the aqueous layer $(1.7 \mathrm{~cm}$ thickness for $250 \mathrm{ml}$ and $3.4 \mathrm{~cm}$ for $500 \mathrm{ml}$ ). Moreover, the lower the wavelength is, the weaker the penetrating potential is. Thus, coupling UV-A and UV-C can pair the germicidal UV-C effect and the greater penetrating power of UV-A. For this reason, it is potentially a better strategy to use a high UV wavelength rather than $254 \mathrm{~nm}$ to sterilize turbid water. In this sense and for the same reasons, Mori et al. (2007) give preference to the use of UVs emitted at $365 \mathrm{~nm}$ (which have a germicidal effect less than that of $254 \mathrm{~nm}$ but have a higher penetrating potential) for sterilization of turbid wastewater.

In order to study the influence of the whole of the above-cited parameters on the efficiency of the optimized choice of coupled wavelengths, a larger volume of effluent $(500 \mathrm{~mL})$ was irradiated for $30 \mathrm{~min}$ at $280 / 365 \mathrm{~nm}$, and log survival ratio was compared to that one obtained with $250 \mathrm{~mL}$ (Fig. 3). In both cases (250 and $500 \mathrm{~mL}$ ), UV exposure has significantly reduced the number of bacteria (KruskalWallis test, $\mathrm{p}<0.05$ followed by multiple comparisons of means by pairs according to the Dunn procedure). However, there is a significant difference between the log survival ratios of the four bacterial types tested in 250 or $500 \mathrm{ml}$ of effluent (Fisher test $\mathrm{p}<0.0001$ ): the bacterial reduction with $250 \mathrm{ml}$ of effluent was in average 1 log higher as compared to $500 \mathrm{ml}$.

The use of UV LEDs for water disinfection eliminates the numerous disadvantages associated with mercury vapor lamps though certain

Table 1

Log reduction and number of bacteria remaining in the effluent $(\mathrm{N})$ after having irradiated $250 \mathrm{ml}$ of this effluent for $30 \mathrm{~min}$ at $280 / 365 \mathrm{~nm}$.

\begin{tabular}{llc}
\hline & Log reduction & $\mathrm{N}(\mathrm{cfu} / 100 \mathrm{ml})$ \\
\hline Mesophilic bacteria & 2.3 & $9.56 \times 10^{4}$ \\
Fecal enterococci & $\mathbf{2 . 3}$ & $5 \times 10^{3}$ \\
Total coliforms & 3.7 & $5.89 \times 10^{3}$ \\
Fecal coliforms & 3.2 & $\mathbf{4 . 4 4} \times \mathbf{1 0}^{\mathbf{2}}$ \\
\hline
\end{tabular}

characteristics of UV (low penetration, UV dose needing long exposure times) have to be taken into account. However, the results obtained here with only one LED per wavelength demonstrate that using UV-LED is a promising alternative method.

\subsection{Chemical assays}

Many synthetic and natural molecules are sensitive to UV-A radiations which induce an oxidation of these molecules. UV radiations cause photochemical transformations of pollutants and also activate the production of reactive intermediates. These intermediates - called photoreactants - are highly reactive and strong oxidizers (oxygen free, peroxide radicals etc.). The molecules may be either oxidized directly by UV radiations (direct photolysis) or indirectly by photoreactants (photocatalysis). Urban wastewaters are characterized by high amounts of organic matter and of chemical compounds recalcitrant to degradation. Here, creatinine - a metabolic waste - and phenol were chosen to test the effects of photooxidation on molecules which represent respectively organic matter and the recalcitrant polluting fraction of the effluent. The coupling UV-A/UV-C can combine these two types of photooxidation of chemical molecules: Chun et al. (2000) showed that,

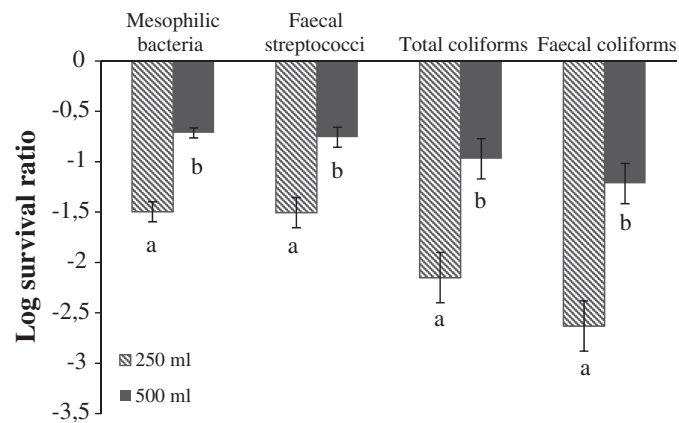

Fig. 3. Log survival ratio of mesophilic bacteria, of fecal enterococci, of total coliforms and of fecal coliforms present in $250 \mathrm{ml}$ and $500 \mathrm{ml}$ of effluent after a $30 \mathrm{~min}$ irradiation. The letters indicate significant differences between each volume irradiated ( $t$ test for two independent samples, $\mathrm{p}<0.0001$ ). 

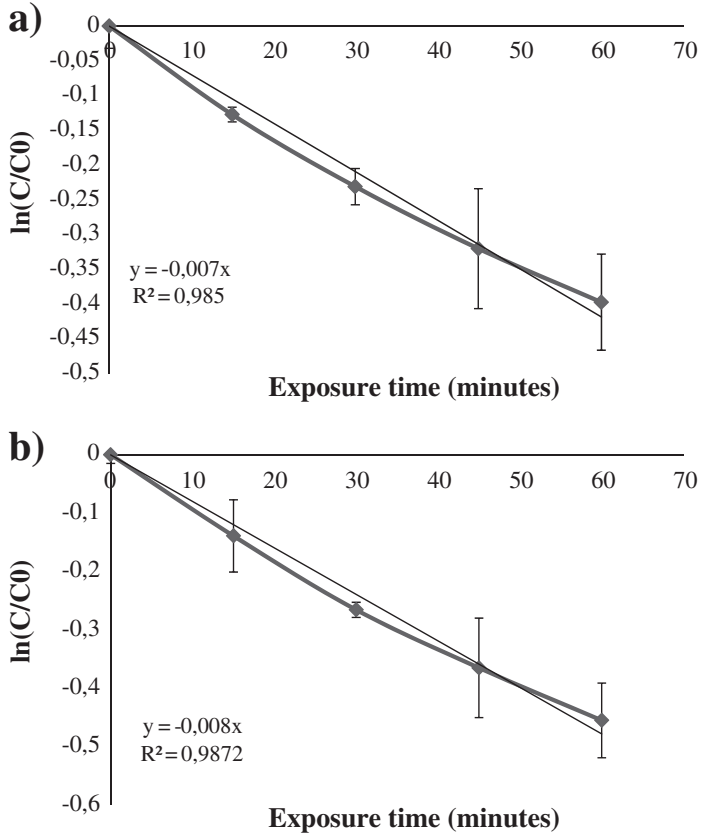

Fig. 4. $\ln (\mathrm{C} / \mathrm{CO})$ ratio for phenol (a) and creatinine (b). $C$ represents the concentration in phenol or creatinine after 15, 30, 45 and $60 \mathrm{~min}$ of exposure time to UV-LEDs emitting at $280 / 365 \mathrm{~nm}$ and C0 represents the concentration of these two molecules before irradiation.

for phenol (which absorbs at $270 \mathrm{~nm}$ ), wavelengths between 200 and $330 \mathrm{~nm}$ caused a direct photolysis of this molecule, whereas only photocatalysis occurred for wavelengths superior to $330 \mathrm{~nm}$. Here, no photoreactant and/or catalyst was added: the various molecules in the effluent can play a role of intermediates in the photocatalysis. Creatinine absorbs at $220 \mathrm{~nm}$ and should therefore undergo direct photolysis by UV-C and photocatalysis by UV-A.

Twenty milligrams of creatinine or phenol were added per liter of effluent (5 $\mathrm{mg}$ in $250 \mathrm{ml}$ of effluent) and were exposed to coupled UV-A/UV-C (280/365 nm) for 0 (control), 15, 30, 45 or $60 \mathrm{~min}$. The samples were analyzed by HPLC after each cycle of UV irradiation. The concentration of creatinine and phenol determined allowed us to calculate a $C / C_{0}$ ratio where $C$ is the creatinine or phenol concentration after irradiation and $\mathrm{C}_{0}$ the initial concentration. Fig. 4 represents the logarithm of $C / C_{0}$ as a function of the exposure time for phenol (Fig. 4a) and creatinine (Fig. $4 \mathrm{~b}$ ). For these two molecules the $\ln \left(\mathrm{C} / \mathrm{C}_{0}\right)$ function is negatively correlated with UV exposure time $\left(r^{2}=0.98\right)$.

Degradation products were not identified in this study but according to the literature they are expected to be organic acids or aromatic byproducts (catechol, hydroquinone, benzoquinone and resorcinol). TOC values remained constant during the study (data not shown), which reveals that degradation of phenol was not complete and the formed products were still organic compounds. In this study, phenol and creatinine degradation kinetics follow a pseudo-first-order rate of $0.007 \mathrm{~min}^{-1}$, which is reliable to results found in the literature (Fogler, 1999; Antoniou and Dionysiou, 2007; Vilhunen and Sillanpää, 2009). However, all these previous results have been obtained in the presence of catalysts $\left(\mathrm{O}_{3}, \mathrm{H}_{2} \mathrm{O}_{2}, \mathrm{O}_{2}\right)$, with 10 or more UV-LEDs, and with synthetic samples. The present study shows that the same order of degradation rate can be reached without any reagents and in the presence of only two LEDs. These promising results could be originated at first from the efficient coupling of 280/365 $\mathrm{nm}$ and also from the presence of natural organic matter or ions in the samples that can act as photoreactants. For example, nitrate and nitrite ions are known to act as precursors responsible for the photo-initiated oxidation of trace organic compounds in natural water (Zepp et al., 1987). However, more tests and monitoring of the intermediate products are needed to determine the degradation pathways involved during photooxidation carried out with coupled wavelengths.

\section{Conclusion}

The use of UV LEDs to substitute mercury vapor lamps in the field of water treatment seems to be a promising alternative. LEDs have many advantages, including the ability to select precisely the wavelength emitted that allows the use of couplings involving UV-C and UVA. This study shows that the coupling UV-A/UV-C achieves a microbial reduction in wastewater greater than when only one type of $U V$ is used. Moreover, only coupling 280/365 and 280/405 nm allow obtaining a significant reduction in mesophilic bacteria though $254 \mathrm{~nm}$ is the wavelength known to have a maximum germicidal effect. Coupling wavelengths $280 / 365 \mathrm{~nm}$ on effluents reduces bacterial contents proportionally to the irradiation time and also oxidizes up to $37 \%$ of creatinine and phenol, used here as model organic contaminants. In further studies, the same experiments should be performed with an experimental set-up containing more LEDs emitting at 280 and $365 \mathrm{~nm}$ and this should be tested on larger volumes of effluent using a pilot reactor in batch or flow.

\section{References}

Antoniou MG, Dionysiou DD. Application of immobilized titanium dioxide photocatalysts for the degradation of creatinine and phenol, model organic contaminants found in NASA's spacecrafts wastewater streams. Catal Today 2007;124: 215-23.

Badawy MI, Ghaly MY, Gad-Allah TA. Advanced oxidation processes for the removal of organo-phosphorus pesticides from wastewater. Desalination 2006;194:166-75.

Chen P-J, Rosenfeld EJ, Kullman SW, Hinton DE, Linden KG. Biological assessments of a mixture of endocrine disruptors at environmentally relevant concentrations in water following UV/ $\mathrm{H}_{2} \mathrm{O}_{2}$ oxidation. Sci Total Environ 2007;376:18-26.

Chevremont A-C, Farnet A-M, Sergent M, Coulomb B, Boudenne J-L. Multivariate optimization of fecal bioindicator inactivation by coupling UV-A and UV-C LEDs. Desalination 2012;285:219-25.

Chun H, Yizhong W, Hongxiao T. Destruction of phenol aqueous solution by photocatalysis or direct photolysis. Chemosphere 2000;41:1205-9.

Close J, Ip J, Lam KH. Water recycling with PV-powered UV-LED disinfection. Renew Energy 2006;31:1657-64.

Crawford MH, Banas MA, Ross MP, Ruby DS, Nelson JS, Boucher R, et al. Final LRDR report: ultraviolet water purification systems for rural environments and mobile applications. Sandia Report; 2005. doi:10.2172/876370.

Decree of August 2nd. Relating to the use of water from treatment plant of urban wastewater for irrigation of crops or gardens. http://www.legifrance.gouv.fr/jopdf/ common/jo_pdf.jsp?numJO $=0 \&$ dateJO $=20100831 \&$ numTexte $=34 \&$ pageDebut $=$ 15828 \&pageFin $=158332010$.

Edelahi MC. Contribution to the study of the in situ degradation of pesticides by advanced oxidation processes involving the use of iron. Application to the phenylureas herbicides. Thesis; Université de Marne-La-Vallée, 2004.

Eischeid AC, Meyer JN, Linden KG. UV disinfection of adenoviruses: molecular indications of DNA damage efficiency. Appl Environ Microbiol 2009;75:23-8.

Evanson M, Ambrose RF. Sources and growth dynamics of fecal indicator bacteria in a coastal wetland system and potential impacts to adjacent waters. Water Res 2006:40:475-86

Fogler HS. Elements of chemical reaction engineering. Upper Saddle River, New Jersey: Prentice-Hall, Inc; 1999.

Hamamoto A, Mori M, Takahashi A, Nakano M, Wakikawa N, Akutagawa M, et al. New water disinfection system using UVA light-emitting diodes. J Appl Microbiol 2007; 103:2291-8.

Hijnen WAM, Beerendonk EF, Medema GJ. Inactivation credit of UV radiation for viruses, bacteria and protozoan (oo)cysts in water : a review. Water Res 2006;40: 3-22.

Kim I, Yamashita N, Tanaka H. Performance of $\mathrm{UV} / \mathrm{H}_{2} \mathrm{O}_{2}$ processes for the removal of pharmaceuticals detected in secondary effluent of a sewage treatment plant in Japan. J Hazard Mater 2009;166:1134-40.

Liberti L, Notarnicola M, Petruzzelli D. Advanced treatment for municipal wastewater reuse in agriculture. UV disinfection: parasite removal and by-product formation. Desalination 2003;152(1-3):315-24.

Linden KG, Thurston J, Schaefer R, Malley JP. Enhanced UV inactivation of adenoviruses under polychromatic UV lamps. Appl Environ Microbiol 2007;73:7571-4.

Molleda P, Blanco I, Ansola G, de Luis E. Removal of wastewater pathogen indicators in a constructed wetland in Leon, Spain. Ecol Eng 2008;33:252-7.

Mori M, Hamamoto A, Takahashi A, Nakano M, Wakikawa N, Tachibana S, et al. Development of a new water sterilization device with a $365 \mathrm{~nm}$ UV-LED. Med Biol Eng Comput 2007;45:1237-41.

Nasser AM, Paulman H, Ktaitzer T, Cikurel H, Zuckerman I, Meir A, et al. UV disinfection of wastewater effluents for unrestricted irrigation. Water Sci Technol 2006;54: 83-8. 
Oguma K, Katayama H, Mitani H, Morita S, Hirata T, Ohgaki S. Determination of pyrimidine dimers in Escherichia coli and Cryptosporidium parvum during UV light inactivation, photoreactivation, and dark repair. Appl Environ Microbiol 2001;67: 4630-7.

Oguma K, Katayama H, Ohgaki S. Photoreactivation of Escherichia coli after low- or medium-pressure UV disinfection determined by an endonuclease sensitive site assay. Appl Environ Microbiol 2002;68:6029-35.

Oppezzo OJ, Pizarro RA. Sublethal effects of ultraviolet A radiation on Enterobacter cloacae. J Photochem Photobiol B 2001;62:158-65.

Palese AM, Pasquale V, Celano G, Figliuolo G, Masi S, Xiloyannis C. Irrigation of olive groves in Southern Italy with treated municipal wastewater: effects on microbiological quality of soil and fruits. Agr Ecosyst Environ 2009;129:43-51.

Recommendation of 22 June 2007 on the collection, transportation and treatment of urban wastewater sanitation, and monitoring of their functioning and effectiveness, and to sewerage schemes receiving a gross load of organic pollution than 1.2 $\mathrm{kg}$ / day of BOD5 (http://www.legifrance.gouv.fr/affichTexte.do;jsessionid=2CEAC50623AE86471BAE1FFB3E3E4A48.tpdjo02v_2?cidTexte=LEGITEXT000006056589\& dateTexte $=20120312$ ).
Rizzo L, Meric S, Guida M, Kassinos D, Belgiorno V. Heterogeneous photocatalytic degradation kinetics and detoxification of an urban wastewater treatment plant effluent contaminated with pharmaceuticals. Water Res 2009;43:4070-8.

Tabrizi GB, Mehrvar M. Pilot-plant study for the photochemical treatment of aqueous linear alkylbenzene sulfonate. Sep Purif Technol 2006;49:115-21.

Vilhunen SH, Sillanpää MET. Ultraviolet light emitting diodes and hydrogen peroxide in the photodegradation of aqueous phenol. J Hazard Mater 2009;161:1530-4.

Vilhunen SH, Särkkä H, Sillanpää MET. Ultraviolet light-emitting diodes in water disinfection. Environ Sci Pollut Res 2009;16:439-42.

Witkin EM. Ultraviolet mutagenesis and inducible DNA repair in Escherichia coli. Bacteriol Rev 1976;40:869-907.

Woo OT, Chung WK, Wong KH, Chow AT, Wong PK. Photocatalytic oxidation of polycyclic aromatic hydrocarbons: intermediates identification and toxicity testing. J Hazard Mater 2009;168:1192-9.

Zepp RG, Hoigné J, Bader H. Nitrate induced photooxidation of trace organic chemicals in water. Environ Sci Technol 1987;21:443-50.

Zepp RG, Callaghan TV, Erickson DJ. Effects of increased solar ultraviolet radiation on biogeochemical cycles. Ambio 1995;24:181-7. 